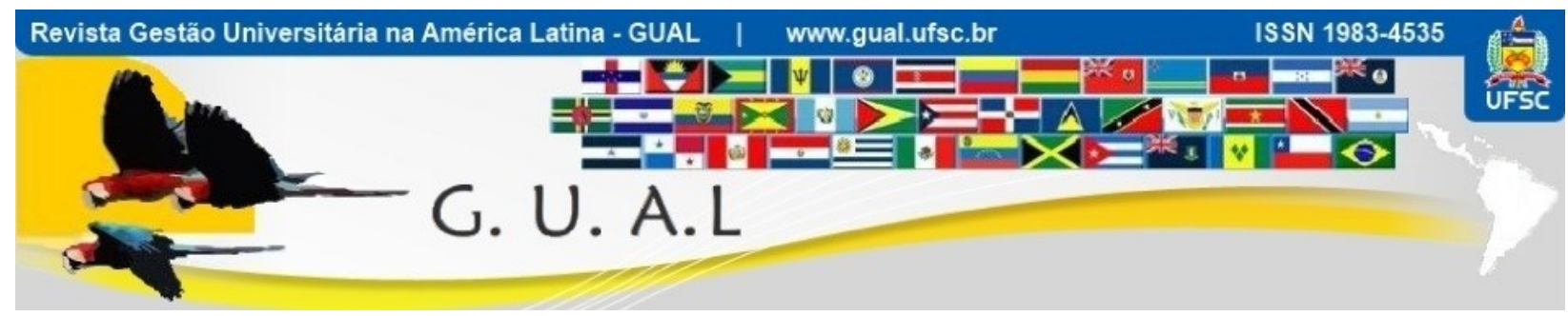

DOI: http://dx.doi.org/10.5007/1983-4535.2017v10n3p140

\title{
POLÍTICAS DE AÇÕES AFIRMATIVAS: ESTUDO DAS RESERVAS DE VAGAS DA UNIVERSIDADE ESTADUAL DE SANTA CRUZ
}

\section{AFFIRMATIVE ACTION POLICIES: A STUDY ON SPOT RESERVATION AT SANTA CRUZ STATE UNIVERSITY}

Diogo Barbosa Figueredo, Mestre Universidade Estadual de Santa Cruz - UESC diogo.uesc@hotmail.com

Marcelo Inácio Ferreira Ferraz, Doutor Universidade Estadual de Santa Cruz - UESC $\underline{\text { mfferraz@uesc.br }}$

Moema Maria Badaró Cartibani Midlej, Doutora Universidade Estadual de Santa Cruz - UESC moema@uesc.br

Recebido em 03/setembro/2015

Aprovado em 23/junho/2017

Sistema de Avaliação: Double Blind Review

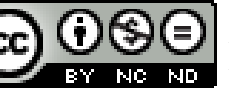

Esta obra está sob uma Licença Creative Commons Atribuição-Uso. 


\title{
RESUMO
}

Esse artigo apresenta um estudo sobre a política afirmativa na universidade pública, esta vem sendo usada como um dos instrumentos de inclusão social dos mais relevantes na história recente do país. O objetivo principal é verificar a trajetória dos estudantes do primeiro processo seletivo com a implantação do sistema de reserva de vagas na Universidade Estadual de Santa Cruz (UESC). Inicialmente, discutem-se as ações desenvolvidas na UESC para garantir que os alunos permaneçam nos cursos até a finalização. Em seguida, analisa-se o perfil socioeconômico dos candidatos que participaram do processo seletivo em 2008 por dois grupos (cota e processo universal), a partir do teste qui-quadrado. Por fim, apresenta as taxas de integralização em ambos os grupos. Os resultados evidenciam o contínuo aumento do número de bolsas que beneficiam para a permanência dos alunos e mostra, também, que mais da metade dos alunos que ingressaram na instituição com as cotas concluíram o curso de graduação. Nesse sentido, é de relevante pertinência trazer novos conhecimentos sobre os alunos que ingressaram na universidade. Com contribuição no campo das políticas de acesso, permanência e conclusão dos alunos da instituição.

Palavras chave: Universidade Pública. Ensino Superior. Educação.

\begin{abstract}
The article contains a study on affirmative policies in public universities, which have become one of the most import social inclusion tools in the country's recent history. The main objective is to track the academic path of the first class under the seat reservation system at Santa Cruz Estate University (UESC). First, there is an analysis of actions taken by the University to guarantee the permanence of students throughout the length of the course. Following, there is a social-economic profile analysis of the 2008 selective process candidates divided into two groups (seat reservation and universal selection process) applying the quisquare test. At last, there is a comparison between graduation rates from both groups. Results show the increasing number of programs that facilitate student permanence and evidentiates that over half of the students who entered university through the seat reservation process actually finished their under-graduate studies. Thus, it is of relevant pertinence the production of deeper studies about these students, which are bound to contribute with access, permanence, and conclusion areas of University policies.
\end{abstract}

Keywords: Public University. Higher Education. Affirmative Action. 


\section{INTRODUÇÃO}

A democratização do Ensino Superior continua a ser um desafio político, social e educacional, exigindo políticas públicas que possam oferecer maior oportunidade de acesso e garantir que os indivíduos concluam os estudos da educação superior. Nesse sentido, Silva (2012) argumenta que a educação superior no Brasil está dentro de um plano nacional de expansão que visam aumentar o número de vagas, desenvolvimento de políticas de permanência estudantil na educação superior e melhoria na qualidade das universidades públicas.

No entanto, ao se considerar que as universidades exercem papel fundamental na democratização e inclusão de pessoas no processo de desenvolvimento com democracia, no momento em que qualifica indivíduos capazes de compreenderem e participarem dos desafios do desenvolvimento econômico, estão cumprindo sua prerrogativa social na formação de valores relacionados com a dignidade e sobrevivência humana. Para Prestes; Jezine e Scocuglia (2012) na democratização do ensino superior é reconhecida a exigência das ações políticas, econômicas e sociais, que são capazes de transpor barreiras na sociedade brasileira que há poucos anos pareciam intransponíveis.

Segundo Anhaia (2013), no Brasil, organismos como a Organização das Nações Unidas (ONU) e a Organização das Nações Unidas para a Educação, a Ciência e a Cultura (UNESCO) tiveram papeis impulsionadores nas discussões dos direitos fundamentais dos indivíduos e na atuação como órgãos de pressão ao governo nacional, com a promoção de eventos e elaboração de documentos, a partir de diversos atores, que atuam na luta pela democratização da educação superior de qualidade. Tais órgãos compreendem a educação como instrumento promotor da liberdade e bom funcionamento e o desenvolvimento da sociedade.

Cada vez mais frequentes, as pressões sociais no Brasil impulsionam a estruturação de políticas para ampliar o acesso das populações aos serviços a que têm direito. Com o respaldo dos movimentos sociais Anhaia (2013) afirma que "as políticas de caráter universalista do Estado brasileiro não acabaram com os efeitos da marginalização e subordinação de grupos específicos, acontecimento de ordem política nacional propiciaram o debate sobre ações afirmativas", assim como a reabertura da política que permitiu a intensificação dos movimentos sociais. 
As políticas afirmativas no ensino superior alcançaram maior visibilidade no Brasil com a instituição do sistema de cotas nas universidades públicas. Destacam-se a Universidade Estadual do Rio de Janeiro que no processo seletivo de 2002/2003 estabeleceu 50\% das vagas para alunos oriundos de escolas pública, negros e pardos (ANHAIA, 2013) e na Universidade do Estado da Bahia em 2002, após a aprovação pelo Conselho Universitário, passou a reservar vagas dos processos seletivos para os estudantes negros de escolas públicas. No âmbito federal a Universidade de Brasília realizou em 2004 seu primeiro processo seletivo com cotas para negros.

Na Universidade Estadual de Santa Cruz - UESC a implantação de reservas de vagas nos cursos de graduação ocorreu a partir do processo seletivo de 2008, após um longo processo de discussão com representantes de movimentos sociais da região de inserção da Instituição, ao longo do ano de 2006, culminando com a aprovação pelo conselho de ensino, pesquisa e Extensão - CONSEPE, em 20/12/2006 e adequação dos procedimentos de seleção, ao longo de 2007.

Assim, as políticas afirmativas nas Instituições públicas de Ensino Superior, vêm se destacando como políticas públicas de inclusão social das mais relevantes na história recente do país, tornando-se importante, também, em outros setores da sociedade como setor produtivo e administrativo das diferentes esferas governamentais.

Sabe-se que o conhecimento da aplicação de políticas públicas bem como a avaliação dos seus resultados é imprescindível para o desenvolvimento, adaptação de formas, instrumentos de ações e funções de planejamento de gestão governamentais. Desta forma, estudos e programas de avaliação e acompanhamento das políticas afirmativas nas Universidades públicas vem sendo desenvolvidas com vista a direcionar ou redefinir ajustes que se façam necessários para garantir a redução das desigualdades e democratizar o acesso ao Ensino Superior. Nesse contexto, este trabalho tem por objetivo verificar a trajetória dos estudantes do primeiro processo seletivo com a implantação do sistema de reserva de vagas na Universidade Estadual de Santa Cruz.

\section{POLÍTICAS DE AÇÕES AFIRMATIVAS}

O conjunto de políticas de ações afirmativas têm o propósito de combater discriminações e desigualdades de grupos historicamente marginalizados, tem tido relevo no amplo debate engendrado no Brasil, a partir de medidas especiais recentes, voltadas a grupos 
vitimados pela exclusão social no país, derivadas de causas étnicas, de sexo, religiosas, culturais, etc.

Historicamente, registros sobre a aplicação dessas políticas foram observados nos meados do século XX nos Estados Unidos, em função da rigidez da classificação de raça, segregação e discriminação contra as pessoas negras, intensificando as relações raciais, levando a inúmeros enfrentamentos nos principais centros urbanos daquele país. Esses fatos levaram à polarização da sociedade norte americana, que, de um lado estavam aqueles favoráveis a uma integração racial e, do outro, os segregacionistas que consideravam a discriminação constitucional, e, não viam necessidade de mudanças do status quo (OLIVEN, 2007).

Esse momento coincide com as reivindicações dos movimentos sociais que lutavam por igualdade e lutava pelos direitos civis, cuja bandeira principal era a extensão da igualdade de oportunidades a todos. Este período, conforme Moehlecke (2002), foi marcado pelo início da eliminação das leis segregacionistas vigentes no país, quando os movimentos negros aparecem como força atuante, com líderes de projeção nacional, além de apoio por parte de liberais e progressistas, unidos numa ampla defesa dos direitos. Assim, os Estados Unidos contemplam aproximadamente meio século de experiência no assunto. Para Oliven (2007, p. 33), a aprovação da Lei dos Direitos Civis dos Estados Unidos, "além de banir todo o tipo de discriminação, concedeu ao governo federal poderes para implementar a dessegregação".

Assim, diante de muitos esforços antidiscriminatórios, foi aprovada pelo Congresso Nacional do EUA em 1964 a Civil Rights Act (Lei dos Direitos Civis), que contém ampla projeção igualitária, planejada para tratar da prática ainda corrente da segregação racial, fortalecendo a aplicação do princípio da "ação afirmativa". De acordo com Peria (2004, p. 25) tal lei "proibia a discriminação racial em um vasto leque de condutas privadas incluindo acomodações públicas, serviços do governo e educação". Há um consenso entre os estudiosos que as ações afirmativas destinadas a promover a igualdade são resultado da iniciativa de entidades públicas e privadas que buscam adequar à política antidiscriminatória amparada pelo governo federal (SILVÉRIO, 2002).

O movimento pelos direitos civis liderado por Martin Luther King Junior pregava a não violência e contou com a integração de muitos cidadãos brancos que eram a favor da integração das pessoas negras na sociedade americana. Após o assassinato do seu líder máximo, em 1968, o movimento passou a ter uma postura mais combativa, e algumas alas, 
com destaque para aqueles de negros muçulmanos, conduzidas por Melcom X, clamavam a separação das raças, que poderia ser alcançada com o retorno à África ou através da ocupação de um território exclusivo fornecido pelo governo. Conforme Oliven (2007) tais atitudes constituíam a antítese da filosofia de integração, que orientou o movimento pelos direitos civis e, de acordo com a nova orientação, os brancos que participavam das lutas pela conquista dos direitos civis, deveriam permanecer fora das lideranças dos movimentos. Nesse contexto surgiram as políticas de ações afirmativas nos Estados Unidos.

Nas décadas seguintes, as políticas de ações afirmativas se expandiram para diversos países além dos Estados Unidos, com experiências verificadas em países da Europa Ocidental, Índia, Malásia, Austrália, Canadá, Nigéria, África do Sul, Argentina, Cuba, Brasil, dentre outros. Na Europa as primeiras orientações deste caráter elaboradas em 1976, tem como expressão “ação ou discriminação positiva” (MOEHLECKE 2002).

As políticas de ações afirmativas são bem mais recentes no Brasil sendo influenciadas por um discurso diferente, onde os negros brasileiros, conforme Oliven (2007, p. 33), estão de certa forma, "conectados nas suas agendas políticas e identidades culturais aos demais negros da diáspora africana. No entanto, levar em conta esse aspecto não significa que as políticas de identidade devam ser iguais para grupos negros de diferentes países, ou mesmo dentro de um único país".

Em 1996, o Congresso Nacional aprovou um projeto de lei que estabelecia o mínimo de $30 \%$ de mulheres nas listas de candidatos dos partidos. Nesse ambiente, o jornal acadêmico "Estudos Femininos" publicou uma coleção de artigos que abordava os vários aspectos ligados à questão das políticas de ações afirmativas como um mecanismo de combater as discriminações contra negros e mulheres. Conforme Peria (2004), em um destes artigos “Ações Afirmativas e Desigualdade Racial no Brasil" aponta a mudança na maneira como o governo federal tem tratado o problema. "Até pouco tempo o discurso das autoridades afirmava-se que o Brasil constituía-se uma democracia racial, onde negros e brancos gozavam de iguais oportunidades e condições de desenvolvimento individual. Neste quadro, apenas as práticas de racismo isoladas constituíam-se um problema a ser resolvido" (PERIA, 2004, p. 29).

As políticas de ações afirmativas como maneira de combater o racismo no Brasil ganharam força na esfera do poder executivo devido as pressões dos movimentos sociais, que forçaram uma resposta do governo federal, e conduziram à criação de diversas organizações 
com objetivo de estudar possibilidades de políticas públicas de ações afirmativas para a população negra. Essas reivindicações aumentaram a visibilidade e circulação do conceito ações afirmativas. Assim, propostas de "políticas de ações afirmativas", "políticas compensatórias", começaram a circular com mais frequência, fazendo o conceito de ações afirmativas ser visto por alguns como opção viável para o combate do problema da desigualdade racial no Brasil (PERIA, 2004).

Destaca-se como marco na implantação de políticas de ações afirmativas no país, a $3^{a}$ Conferência Mundial das Nações Unidas contra o Racismo, a discriminação Racial, a Xenofobia e a Intolerância Correlata (CMR) ocorrida em Durban, África do Sul no ano de 2001, sendo que a mobilização se intensificou em diversos setores da sociedade brasileira na formulação do documento oficial para o evento, tal como: ONGs, entidades do Movimento Negro e outros movimentos sociais, setores do governo, academia, mídia, etc., além do apoio do presidente Cardoso, à proposta de cotas ou outros tipos de ações afirmativas que promovessem o acesso do negro à universidade pública. A partir de então, segundo Peria (2004), as questões discutidas foram essenciais para o estabelecimento das cotas e adesão dos negros a universidade pública.

Neste início de século XXI, incluir os diversos representantes da sociedade brasileira em seus assentos, está sendo o maior desafio da universidade pública. Segundo Gonçalves (2011), tornou-se inevitável uma reforma nos meios de acesso para os menos favorecidos ao ensino público, gratuito e de qualidade. Desde o início deste século vem ocorre transformações na educação superior e as universidades públicas buscam alternativas ao modelo tradicional, adotando formas diferenciadas e ajustes a realidades regionais no processo de escolha de seus estudantes.

Destacam-se as experiências voltada para a ampliação do acesso de estudantes negros na universidade, com a adoção do sistema de cotas por várias Instituições de Ensino Superior (IES). Essas ações, conforme Peria (2004) estão largamente ligadas as ações que se iniciaram em 2001 e se intensificaram em 2002 e 2003, com uma paulatina proliferação de políticas afirmativas para o ingresso do negro na universidade pública.

Nesse contexto, em 2003 foi realizado o primeiro processo seletivo no país, voltado para atender a dois grupos distintos, na Universidade Estadual do Rio de Janeiro (UERJ). O primeiro, aquele que não desejava ou podia concorrer no sistema de cotas e o segundo para aqueles que desejavam se beneficiar com as cotas, sendo que este segundo grupo tinha que 
cumprir a determinação da Universidade, que destinava 50\% das vagas para alunos de escola pública e negros, e em seguida, foi reservada mais 10\% das vagas para deficientes físicos através da Lei 4061 de 02 de Janeiro de 2003 (GONÇALVES, 2011).

Desde a implantação das cotas na UERJ inúmeras outras instituições adotaram o mesmo procedimento, destacando o caso da primeira instituição federal, a Universidade de Brasília (UNB) no ano de 2004 na modalidade cotas para negros, e outro caso, a Universidade do Estado da Bahia (UNEB) em 2003 adotando 40\% das vagas para alunos negros das escolas públicas.

\subsection{ASPECTOS CONCEITUAIS DO TERMO AÇÕES AFIRMATIVAS}

A ação afirmativa pressupõe mais de uma política pública em sua implementação, tendo como objetivo principal a mudança estrutural, além de criar uma intervenção social adequada no ensino superior, no emprego e, principalmente, nos meios de comunicação. Em resumo, para Santos (2005) a grande ideia das ações afirmativas é firmar-se como uma das políticas mais avançadas, concretizar o princípio da igualdade, fazendo com que todos tenham condições de disputar as oportunidades disponíveis na sociedade.

As políticas de ações afirmativas representam uma mudança na postura do Estado, que em nome da suposta neutralidade, formulava e aplicava políticas governamentais indistintamente, sem considerar fatores como: sexo, cor, raça, etc. Com a nova postura, o Estado passou a considerar esses fatores ao regular o acesso aos estabelecimentos educacionais. Assim, ao invés de conceber políticas públicas que beneficiariam a população indistintamente, o Estado passa a levar em consideração as características de raça, cor, sexo na implementação de suas decisões. Isso, para evitar discriminação, que inegavelmente tem um fundo histórico e cultural, e não raro tendem a se perpetuar as iniquidades sociais (GOMES, 2003).

As ações afirmativas se definem como políticas públicas (e privadas) visando à concretização do princípio constitucional da igualdade material e neutralização dos efeitos discriminatórios. Em sua compreensão, a igualdade deixa de ser apenas um princípio jurídico a ser respeitado por todos, e passa a ser um objetivo constitucional a ser alcançado pelo Estado e pela sociedade. Conforme Gomes (2003, p. 6) podem ser "impostas ou sugeridas pelo Estado, por seus entes vinculados e até mesmo por entidades puramente privadas, elas 
visam a combater não somente as manifestações flagrantes de discriminação, mas também a discriminação de fato, de fundo cultural, estrutural, enraizada na sociedade".

Sousa (2006) diz que são muitas as controvérsias sobre as ações afirmativas, iniciando-se pelo significado do próprio nome. O significado pode designar um conjunto de iniciativas ou políticas, com incentivo do Estado, a fim de promover a igualdade material em relação a indivíduos, grupos, ou segmentos da sociedade que foram marginalizados, com o objetivo de eliminar as disparidades e concretizar a dignidade da pessoa humana.

Desta maneira, o desenvolvimento destas políticas tem por finalidade proteger minorias e grupos que foram historicamente discriminados, em determinada sociedade, seja em virtude da raça ou em virtude da condição financeira.

A ação afirmativa visa remover barreiras, formais e informais, que impeçam o acesso de certos grupos ao mercado de trabalho, universidades e posições de liderança. Em termos práticos, as ações afirmativas incentivam as organizações a agir positivamente a fim de favorecer pessoas de segmentos sociais discriminados a terem oportunidade de ascender a postos de comando (OLIVEN, 2007, p. 31).

Neste sentido, segundo Oliven (2007), a pouca representação das minorias em instituições de alto prestígio social pode ser considerada como reflexo da discriminação do passado. Com isso, visa-se então, por um período determinado, a criação de ferramentas que incentive os grupos minoritários a galgarem melhores posições nessas instituições. Isso, na busca do equilíbrio percentual entre cada camada da população e a composição dos grupos de poder nas diversas instituições que compõem a sociedade.

Tais mediadas visam promover a igualdade em sentido material, entendida como isonomia de fato e não apenas formal , buscando afastar uma situação de discriminação em que um grupo específico foi colocado em situação de desvantagem social, por pertencer a tal conjunto, que é discriminado em virtude da cor, credo, gênero, condição econômica, etc. Para tanto, lança-se mão de uma iniciativa estatal cujo foco é equilibrar as forças existentes no jogo da sociedade, a qual exclui os grupos fracos, possibilitando igualdade de condições em disputar o acesso a serviços ou oportunidades de um Estado (MARTINS, 2007).

Assim, na visão de Santos (2005) ação afirmativa é tratar de modo preferencial os grupos que foram historicamente marginalizados, para que lhe sejam concedidas condições equivalentes aos privilegiados da exclusão, diferenciando-se drasticamente de redistribuição, não sendo a simples busca pela diminuição de carência econômica, mas sim medidas de 
justiça que tem por base considerações históricas no reconhecimento do menosprezo da identidade de tais grupos discriminados.

Para Domingues (2005) a implementação das ações afirmativas, dentre os quais as políticas de reservas de vagas, decreta o reconhecimento do preconceito ou discriminação racial. A vigência de tais programas são as provas cabais da existência do racismo e um problema específico com o negro no país, pois, caso contrário não havia necessidade de medidas reparatórias destinadas a este segmento da população.

Enfim, o tratamento preferencial reserva uma característica essencial em seu conceito. Fala-se de um posicionamento do Estado de maneira efetiva e positiva e do uso do direito como instrumento de transformação social. As políticas afirmativas abrangem as políticas públicas que visam combater o racismo existente na sociedade e corrigir seus efeitos históricos, idealizando a igualdade de acesso a bens fundamentais em uma democracia, como educação e emprego (SANTOS, 2005).

\section{PROCEDIMENTOS METODOLÓGICOS}

O objeto de estudo deste trabalho é a Universidade Estadual de Santa Cruz - UESC no contexto das reservas de vagas. Os dados foram retirados dos questionários do vestibular 2008 da UESC, disponibilizados pela Gerência de Seleção e Orientação - GESEOR. As variáveis do questionário sociocultural e econômico que compôs o material de inscrição no processo seletivo da UESC, composto por questões divididas em quatro grupos: Identificação, Informações econômicas, Informações escolares e Informações socioculturais.

Além das informações dos questionários sociocultural e econômico, foram cedidos pela GESEOR dados sobre as concorrências dos candidatos por vagas dos processos seletivos, de 2008 a 2013, desagregadas em reservas de vagas, processo universal, semestre de entrada no curso, sexo e turno, bem como, as informações de bolsas de estudo concedidas pela Assessoria Estudantil (ASSEST).

Para análise dos dados, foram usadas estatísticas descritivas e testes de Qui Quadrado, este consiste em um teste de hipóteses, não paramétrico, tem como função encontrar a associação entre duas variáveis e avaliar se existe relação entre as variáveis qualitativas.

Para estabelecer a relação entre as variáveis socioculturais e econômicas, realizou-se uma análise bivariada entre cada variável do questionário socioeconômico e a forma de 
seleção (cotas e processo universal), através do teste não-paramétrico qui-quadrado. A análise foi feita ao nível de $5 \%$ de significância ( $\mathrm{p}$-valor $<0,05)$.

\section{AÇÕES AFIRMATIVAS NA UNIVERSIDADE ESTADUAL DE SANTA CRUZ}

A Universidade Estadual de Santa Cruz (UESC) buscou democratizar o acesso ao ensino superior ao implementar políticas afirmativas, para melhor contemplar sua área de atuação. A Política de Assistência Estudantil baseou-se nos princípios de inclusão social, da democracia e da qualidade acadêmica, voltados para formação integral dos discentes. Para atender esse propósito, foram traçadas algumas estratégias de ação, como: permanência - para atender necessidade de transporte, alimentação, saúde, creche e condições para portadores de necessidades especiais; desempenho acadêmico - com bolsas (monitoria, pesquisa e extensão), estágios remunerados, ensino de línguas, inclusão digital, fomento à participação político-acadêmico e acompanhamento pedagógico; por fins incentivos de práticas de cultura esporte e lazer.

A fim de materializar as propostas de Assistência Estudantil, em 2006, após três anos com o projeto experimental "Bantuiê" e reuniões mensais com mais de 20 representantes de entidade regionais, foi definido o primeiro passo para a reserva de vagas no processo seletivo para ingresso na universidade, ação compatível com a nova política de Assistência Estudantil que começava a ser implementada. Continuando tais ações, no ano de 2008, foi criada a Assessoria de Assistência Estudantil (ASSEST) com o objetivo de acompanhar e articular ações que possibilitem o acesso, a permanência e a conclusão dos cursos pelos estudantes com baixa renda matriculados nos cursos de graduação.

No vestibular de 2008 foi posta em prática a política de inclusão social e ações afirmativas para permanência dos ingressantes na UESC. Foram instituídas as cotas através da Resolução 064/2006, que reservava metade das vagas para todos os cursos de graduação. Ainda com vista a inclusão, através do Programa de Isenção de Taxas de Inscrição para o Vestibular, no referido ano, beneficiou um total de 777 (setecentos e setenta e sete) candidatos.

Para garantir a continuidade das políticas afirmativas e diante da necessidade de apoio às situações de ordem psicossocial vividas pelos discentes, foram instituídas algumas medidas adicionais como: auxílio financeiro e de acolhimento tendo em vista o melhor desempenho acadêmico dos alunos. A política de concessão de Bolsa Permanência foi implantada em 
2008, modalidade essa que visava a melhoria na condição de vida dos estudantes, a fim de garantir sua permanência no curso de nível superior. Conforme a Tabela 12, em 2013 foram contemplados 1.030 estudantes com a bolsa permanência o que significa um aumento de $118,2 \%$ em relação a 2008 .

Tabela 1 Número de bolsas institucionais de permanência para estudantes de graduação, UESC, no período de 2008 a 2013

\begin{tabular}{lcccccc}
\hline \multirow{2}{*}{ Critérios de distribuição } & \multicolumn{5}{c}{ Bolsas (Unidade) } \\
\cline { 2 - 7 } & 2008 & 2009 & 2010 & 2011 & 2012 & 2013 \\
\hline Deficiência Auditiva & - & - & 1 & 1 & 5 & 6 \\
Deficiência Motora & 2 & 4 & 4 & 3 & 3 & 2 \\
Deficiência Visual & 2 & 2 & - & 3 & 2 & 3 \\
Comunidade Remanescente de Quilombo & 0 & 1 & 1 & 2 & 7 & 12 \\
Índio reconhecido pela FUNAI & 5 & 8 & 12 & 11 & 23 & 32 \\
Outras modalidades & 463 & 489 & 532 & 910 & 940 & 975 \\
Total de bolsas disponibilizadas & 472 & 504 & 550 & 930 & 980 & 1030 \\
\hline
\end{tabular}

Fonte: ASSEST/UESC, 2014.

A UESC concedeu Bolsas de Permanência no valor de R\$270,00 (duzentos e setenta reais), no ano de 2013, aos estudantes de baixa renda, com o objetivo de contribuir para a melhor qualidade de vida do discente, permanência e conclusão do curso e diminuir a evasão estudantil motivada por questões de dificuldade financeira.

No ano de 2011, a UESC implantou o Auxílio Moradia, destinado a discentes que tiveram que deixar seu ambiente familiar em cidades distante da sede universitária e passaram a residir na região para a realização do curso universitário. Também, diariamente, disponibiliza refeições no Restaurante Universitário em três turnos para atender a comunidade acadêmica, sendo que em 2014, do valor destas, $\mathrm{R} \$ 1,00$ (um real) era pago pelo discente e o restante subsidiado pela UESC. São oferecidas 200 refeições no café da manhã, 900 refeições no almoço e 200 refeições no jantar com o subsídio da universidade, prática que visa assegurar-lhes melhores condições alimentícias.

Portanto, a UESC promove políticas de inclusão social e ações afirmativas que possibilitam aos estudantes de classes sociais menos favorecidas ingressarem na educação superior. Além do ingresso através das cotas, a UESC aderiu ao Sistema de Seleção Unificada (SiSU), definindo que no processo seletivo de 2012 , o total de $50 \%$ das vagas dos cursos de graduação fossem preenchidas por meio do SiSU e o restante por meio do Vestibular 
tradicional. A partir de 2013, todas as vagas do processo seletivo foram preenchidas através do Sistema de Seleção Unificada.

\subsection{PERFIL DOS PRIMEIROS ALUNOS BENEFICIADOS PELAS AÇÕES AFIRMATIVAS DA UESC}

No ano de 2008, 13.662 candidatos inscreveram-se no processo seletivo de acesso aos cursos de graduação da UESC, nesse universo as mulheres foram maioria, representando 57\% dos candidatos. Do total de candidatos, 1.317 (9,64\%) foram classificados e aprovados no referido exame, isso corresponde que mais de $90 \%$ dos candidatos ficaram de fora do limite de vagas oferecidas pela instituição.

As mulheres representam maioria dos candidatos que participaram do processo universal 55,9\% dos candidatos. Daqueles que optaram pelo sistema de cotas as mulheres representam 58,2\% dos candidatos Os dados demonstram que as mulheres demandaram mais os cursos de graduação da UESC e maior participação no sistema de cotas, conforme Tabela 13.

Tabela 2 Distribuição por sexo dos candidatos que participaram do processo seletivo (vestibular) da Universidade Estadual de Santa Cruz em 2008, conforme forma de seleção (Processo Universal e Cota)

\begin{tabular}{lcccccc}
\hline \multirow{2}{*}{ Sexo } & \multicolumn{7}{c}{ Candidatos } \\
\cline { 2 - 7 } & Processo Universal & $\%$ & Cota & $\%$ & Total & $\%$ \\
\hline Feminino & 3986 & 55,9 & 3800 & 58,2 & 7786 & 57,0 \\
Masculino & 3142 & 44,1 & 2734 & 41,8 & 5876 & 43,0 \\
Total & 7128 & 100 & 6534 & 100 & 13662 & 100 \\
\hline
\end{tabular}

Fonte: Elaborado a partir de dados da GESEOR/UESC.

Apesar da procura pelos cursos de graduação da UESC ser menor pelos candidatos do sexo masculino, estes conseguiram ter melhor desempenho representando maioria dos classificados do processo seletivo de 2008 , sendo $51,3 \%$ dos selecionados do sexo masculino e $48,7 \%$ do sexo feminino.

Quanto à escolha do idioma da prova, entre o total de candidatos, 65,6\% optaram pelo Espanhol, 0,2\% o Francês e 34,2\% o Inglês. Assim, 70,5\% dos classificados neste vestibular optaram pelo Espanhol, 0,1\% pelo Francês e 29,5 pelo Inglês (Tabela 14). 
Apesar do Inglês ser a idioma oferecido nas escolas das series iniciais (Ensino fundamental e médio), os candidatos optam em sua maioria pelo Espanhol, possivelmente pela maior semelhança dessa Língua com o Português, língua de origem dos candidatos.

Tabela 3 Distribuição por tipo da prova de línguas dos candidatos que participaram do processo seletivo (vestibular) da Universidade Estadual de Santa Cruz em 2008

\begin{tabular}{lcccccc}
\hline \multirow{2}{*}{ Língua } & \multicolumn{7}{c}{ Candidatos } \\
\cline { 2 - 7 } & Classificados & $\%$ & Não classificados & $\%$ & Total & $\%$ \\
\hline Espanhol & 928 & 70,5 & 8038 & 65,1 & 8966 & 65,6 \\
Francês & 1 & 0,1 & 26 & 0,2 & 27 & 0,2 \\
Inglês & 388 & 29,5 & 4281 & 34,7 & 4669 & 34,2 \\
\hline Total & 1317 & 100 & 12345 & 100 & 13662 & 100 \\
\hline
\end{tabular}

Fonte: Elaborado a partir de dados da GESEOR/UESC

Do total de candidatos, 66\% ingressaram na UESC pelo processo universal, ou seja, não necessitaram das cotas. Por outro lado, mesmo sendo destinadas $50 \%$ das vagas da instituição aqueles que optassem pelas cotas, estes representavam apenas 34\%. Isso justificase pelo fato da baixa procura em determinados cursos por aqueles candidatos que poderiam usufruir dessa ação afirmativa.

A seguir são apresentados os resultados do teste de hipótese qui quadrado. Esse consiste em um teste não paramétrico pois não depende de parâmetros populacionais como média e variância. O princípio básico deste método é comparar proposições, ou seja, as possíveis divergências entre as frequências observadas e esperadas para cada evento. Foi considerada a categoria forma de seleção (cotas e processo universal), aplicou-se o teste aos quatro grupos de questões (Identificação, informações escolares, informações socioculturais e informações econômicas) que compõem o questionário socioeconômico e cultural respondido no ato da inscrição no referido processo seletivo da UESC.

Conforme Tabela 15, ao se aplicar o teste qui quadrado às questões do questionário socioeconômico, mostrou-se predominantemente diferenças estatisticamente significativas, ou seja, tais questões relacionadas a forma de seleção formaram grupos estatisticamente semelhantes. O grupo de questões de "Identificação" os p-valores mostraram significância estatisticamente (abaixo de 0,05 ) ao nível de 5\% para todas as questões da categoria sistema de cotas e processo universal.

Do total de inscritos no processo seletivo (vestibular) 2008 da UESC, 90,3\% dos candidatos que participaram da seleção por cotas foram provenientes da zona urbana, 35,9\% 
da cor preta, $53,6 \%$ parda e 7,4\% branca, quanto a origem étnica ou raça $53,0 \%$ negra e $83,1 \%$ declararam ser afrodescendente.

Tabela 4 Teste qui quadrado para os candidatos participantes do primeiro vestibular com cotas da Universidade Estadual de Santa Cruz, considerando as variáveis do grupo "Identificação" do questionário socioeconômico, conforme sistema de seleção, em 2008

\begin{tabular}{|c|c|c|c|}
\hline \multirow{2}{*}{ Identificação } & \multicolumn{2}{|c|}{ Seleção } & \multirow[b]{2}{*}{ P-valor } \\
\hline & Cota & $\mathrm{PU}$ & \\
\hline \multicolumn{4}{|l|}{ Procedência: } \\
\hline Zona urbana & 90,3 & 97,1 & 0,000 \\
\hline Zona rural & 9,7 & 2,9 & \\
\hline \multicolumn{4}{|c|}{ Qual é a sua cor ou raça? } \\
\hline Preta & 35,9 & 11,3 & 0,000 \\
\hline Parda & 53,6 & 53,6 & \\
\hline Branca & 7,4 & 30,8 & \\
\hline Amarela & 1,5 & 3,7 & \\
\hline Indígena & 1,6 & 0,6 & \\
\hline \multicolumn{4}{|c|}{ Qual é a sua origem étnica ou racial? } \\
\hline Negra & 53,0 & 18,5 & 0,000 \\
\hline Branca & 5,8 & 26,4 & \\
\hline Mestiça & 37,2 & 50,3 & \\
\hline Amarela & 1,6 & 3,0 & \\
\hline Indígena & 2,5 & 1,8 & \\
\hline \multicolumn{4}{|c|}{ Você se declara afrodescendente? } \\
\hline Não & 16,9 & 47,1 & 0,000 \\
\hline Sim & 83,1 & 52,9 & \\
\hline
\end{tabular}

Fonte: Elaborado a partir de dados da GESEOR/UESC.

Na Tabela 16 que se refere ao grupo de questões "Informações Escolares” os p-valores mostraram-se significativos (abaixo de 0,05 ) para todas as questões da categoria sistema de cotas e processo universal.

Do total de inscritos no processo seletivo, os que participaram da seleção geral por cotas $22,3 \%$ concluiu o ensino médio no ano anterior, $20 \%$ há dois ano e $23,1 \%$ sete anos ou mais. Quanto ao tipo de estabelecimento que cursou o ensino médio 93,3\% todo em escola pública, $77,1 \%$ na modalidade científico padrão e 56,8\% frequentou algum curso prévestibular. Quanto ao principal fator que levou a escolha do curso 70,7\% foi por afinidade pessoal e realização pessoal e 96,4\% considera-se decidido quanto a opção. Em relação a 
escolaridade das mães $9 \%$ das mães não são alfabetizadas, $28,1 \%$ ensino médio completo e apenas $4,6 \%$ superior completo.

Referindo-se aos que participaram da seleção pelo processo universal, 37,6\% concluiu o ensino médio no ano anterior e $21,6 \%$ há dois anos, $27,2 \%$ cursou todo o ensino médio em escola pública, $56,2 \%$ todo em escola particular, $88,6 \%$ na modalidade científico padrão e $51,5 \%$ frequentou algum curso pré-vestibular. Quanto ao principal fator que o levou a escolher o curso 73,3\% demonstraram afinidade pessoal, realização profissional e 94,5\% se consideram decididos. Quanto ao grau de escolaridade das mães 1,7\% das mães não são alfabetizadas. 20,5\% possuem ensino médio completo e $13,5 \%$ superior completo.

Alguns estudos semelhantes foram desenvolvidos por Velloso (2005), entre os candidatos cotistas que têm mães com nível superior varia entre as áreas de conhecimento e grupos de cursos, mas em geral a frequência de mães com nível superior diminui à medida que decresce o nível médio do desempenho no vestibular. Já no trabalho de Cardoso (2008), quando considerado a escolaridade da mãe como um indicador social para os alunos ingressantes no segundo ano após a adoção das reservas de vagas na $U n B$, não apresentou associação com os índices de evasão dos cotistas.

Tabela 5 Teste qui quadrado para os candidatos participantes do primeiro vestibular com cotas da Universidade Estadual de Santa Cruz, considerando as variáveis do grupo "Informações escolares" do questionário socioeconômico, conforme sistema de seleção, em 2008

\begin{tabular}{|c|c|c|c|}
\hline \multirow{2}{*}{ Informações escolares } & \multicolumn{2}{|c|}{ Seleção } & \multirow[b]{2}{*}{ P-valor } \\
\hline & Cota & PU & \\
\hline \multicolumn{4}{|l|}{ Ano em que você concluiu o ensino médio } \\
\hline Ano anterior & 22,3 & 37,6 & 0,000 \\
\hline 2 anos & 20,8 & 21,6 & \\
\hline 3 anos & 13,4 & 12,6 & \\
\hline 4 anos & 8,9 & 7,0 & \\
\hline 5 anos & 6,3 & 4,2 & \\
\hline 6 anos & 5,1 & 3,1 & \\
\hline 7 anos & 18,6 & 10,5 & \\
\hline 8 anos ou mais & 4,5 & 3,3 & \\
\hline \multicolumn{4}{|c|}{ Em que tipo de estabelecimento você cursou o Ensino Médio? } \\
\hline Maior parte na escola pública & 4,3 & 7,1 & 0,000 \\
\hline Maior parte na escola particular & 0,6 & 9,5 & \\
\hline Todo na escola pública & 93,3 & 27,2 & \\
\hline Todo na escola particular & 1,7 & 56,2 & \\
\hline \multicolumn{4}{|c|}{ Que modalidade de Ensino Médio ( $2^{\circ}$ grau) você concluiu ou está concluindo? } \\
\hline Científico ou padrão & 77,1 & 88,6 & 0,000 \\
\hline
\end{tabular}


Técnico ou profissionalizante

$7,8 \quad 4,1$

Magistério

$11,1 \quad 3,4$

Supletivo

$3,9 \quad 3,8$

Frequentou algum curso pré-vestibular?

Não

$43,1 \quad 48,5$

0,000

Sim, particular

$22,9 \quad 44,2$

Sim, programas populares

$33,9 \quad 7,3$

Qual o principal fator que o(a) levou a escolher o curso pelo qual está optando?

Mercado de trabalho garantido

$11,5 \quad 10,2 \quad 0,001$

Pouca exigência e de fácil conclusão

$0,4 \quad 0,2$

Afinidade pessoal, realização pessoal

$70,7 \quad 73,3$

Inexistência do curso pretendido

$3,1 \quad 2,7$

Conciliar a profissão e boa remuneração

$3,9 \quad 4,2$

Dificuldade de aprovar em outro curso

$0,7 \quad 0,7$

Permite conciliar com outros afazeres

$1,8 \quad 1,1$

Importante para o desenvolvimento do país

$3,4 \quad 2,8$

Outro motivo

$4,5 \quad 4,7$

Quanto a sua primeira opção, você se considera:

Decidido(a)

$96,4 \quad 94,5 \quad 0,000$

Indeciso(a)

$3,6 \quad 5,5$

Grau de escolaridade da mãe ou responsável

Não alfabetizada

Ensino fundamental incompleto

$9,0 \quad 1,7$

$37,1 \quad 10,7$

Ensino fundamental completo

$7,7 \quad 4,3$

Ensino médio incompleto

$8,8 \quad 6,2$

Ensino médio completo

$28,1 \quad 39$

Superior incompleto

$4,7 \quad 12,3$

Superior completo

$4,6 \quad 25,7$

Fonte: Elaborado a partir de dados da GESEOR/UESC.

Conforme Tabela 17 do grupo de questões "Informações Socioculturais" os p-valores mostraram-se significativos (abaixo de 0,05 ) para todas as questões da categoria sistema de cotas e processo universal.

Do total de candidatos, os que participaram da seleção por cotas $41,9 \%$ lê em média de três a cinco livros por ano, $52,6 \%$ usa a televisão e $24,4 \%$ a internet para se manterem informado, sendo que $31,1 \%$ possuem internet em casa e $60,7 \%$ acessam em outros locais. Dos que participaram pelo processo universal 40,8\% leem, também, de três a cinco livros por ano, $41,6 \%$ usa televisão e $36,9 \%$ a internet para se manterem informados. Sendo que $66,7 \%$ tem acesso à internet em casa. 
Tabela 6 Teste qui quadrado para os candidatos participantes do primeiro vestibular com cotas da Universidade Estadual de Santa Cruz, considerando as variáveis do grupo "Informações Socioculturais" do questionário socioeconômico, conforme sistema de seleção, em 2008

\begin{tabular}{|c|c|c|c|}
\hline \multirow{2}{*}{ Informações socioculturais } & \multicolumn{2}{|c|}{ Seleção } & \multirow[b]{2}{*}{ P-valor } \\
\hline & Cota & $\mathrm{PU}$ & \\
\hline \multicolumn{4}{|c|}{ Excetuando os escolares, quantos livros, em média, você lê por ano? } \\
\hline Nenhum & 1,7 & 2,5 & 0,013 \\
\hline 1 a 2 & 24,3 & 24,5 & \\
\hline 3 a 5 & 41,9 & 40,8 & \\
\hline 6 a 10 & 22,3 & 21,6 & \\
\hline 11 a 20 & 6,6 & 7,4 & \\
\hline Mais de 20 & 3,2 & 3,4 & \\
\hline \multicolumn{4}{|c|}{ Qual o meio que você mais utiliza para se manter informado(a)? } \\
\hline Televisão & 52,6 & 41,6 & 0,000 \\
\hline Rádio & 0,8 & 0,4 & \\
\hline Jornal & 12,4 & 7,4 & \\
\hline Revistas & 8,5 & 12,1 & \\
\hline Conversas & 1,3 & 1,7 & \\
\hline Internet & 24,4 & 36,9 & \\
\hline \multicolumn{4}{|l|}{ Você tem acesso à Internet? } \\
\hline Não & 8,3 & 3,1 & 0,000 \\
\hline Sim, em casa & 31,1 & 66,7 & \\
\hline Sim, apenas em outros locais & 60,7 & 30,2 & \\
\hline
\end{tabular}

Fonte: Elaborado a partir de dados da GESEOR/UESC.

Conforme Tabela 17, ao se referir ao grupo de questões "Informações Econômicas" os p-valores mostraram-se significativos (abaixo de 0,05 ) para todas as questões da categoria sistema de cotas e processo universal.

Os que participaram da seleção por cotas 53,7\% responderam não estar trabalhando atualmente, $78,7 \%$ não recebe benefício de algum programa social do governo. Quanto a renda total das famílias 33,9\% recebe de um a dois salários mínimos e 29,1\% recebe de dois a três salários mínimos. Sendo que 53,5\% não trabalha e recebe ajuda da família.

Dos que participaram da seleção pelo processo universal, 75\% responderam não está trabalhando atualmente, 4,7\% das famílias recebe benefícios de algum programa social do governo. Em relação a renda mensal de toda família 30,9\% recebe de três a cinco salários mínimos, 25,4\% recebe de 5 a 10 salários mínimos, 76,4\% não trabalha e recebe ajuda familiar. 
Tabela 7 Teste qui quadrado para os candidatos participantes do primeiro vestibular com cotas da Universidade Estadual de Santa Cruz, considerando as variáveis do grupo "Informações Econômicas" do questionário socioeconômico, conforme sistema de seleção, em 2008

\begin{tabular}{|c|c|c|c|}
\hline \multirow{2}{*}{ Informações Econômicas } & \multicolumn{2}{|c|}{ Seleção } & \multirow[b]{2}{*}{ P-valor } \\
\hline & Cota & $\mathrm{PU}$ & \\
\hline \multicolumn{4}{|l|}{ Você está trabalhando atualmente? } \\
\hline Não & 53,7 & 75,0 & 0,000 \\
\hline Sim, trabalho eventualmente & 7,9 & 4,9 & \\
\hline Sim, trabalho em tempo parcial (até $30 \mathrm{~h}$ semanais) & 13,1 & 8 & \\
\hline Sim, trabalho em tempo integral & 25,4 & 12,1 & \\
\hline \multicolumn{4}{|c|}{ Sua família é beneficiária de algum Programa Social do Governo } \\
\hline Não & 78,7 & 95,3 & 0,000 \\
\hline Sim & 21,3 & 4,7 & \\
\hline \multicolumn{4}{|c|}{ Qual a renda mensal de toda a sua família? (somando todas as fontes de renda bruta). } \\
\hline Até meio salário mínimo & 1 & 0,2 & 0,000 \\
\hline De meio a um salário mínimo & 9 & 1,6 & \\
\hline Mais de 1 até 2 salários mínimos & 33,9 & 10,8 & \\
\hline Mais de 2 até 3 salários mínimos & 29,1 & 18 & \\
\hline Mais de 3 até 5 salários mínimos & 20,2 & 30,9 & \\
\hline Mais de 5 até 10 salários mínimos & 6 & 25,4 & \\
\hline Mais de 10 até 20 salários mínimos & 0,7 & 10 & \\
\hline Mais de vinte salários mínimos & 0,2 & 3,3 & \\
\hline \multicolumn{4}{|l|}{ Qual a sua participação na renda familiar? } \\
\hline Não trabalho, recebo ajuda família & 53,4 & 76,4 & 0,000 \\
\hline Trabalho e recebo ajuda da família & 8,3 & 7,8 & \\
\hline Trabalho e não recebo ajuda da família & 6,5 & 3,2 & \\
\hline Trabalho e contribuo em parte na renda familiar & 24,4 & 9,3 & \\
\hline Trabalho e sou o responsável pela família & 7,3 & 3,2 & \\
\hline
\end{tabular}

Fonte: Elaborado a partir de dados da GESEOR/UESC.

Ao analisar a Tabela 22, dentre os alunos que foram classificados e aprovados pelo processo universal, dos cursos de Bacharelado em Matemática e Bacharelado em Física, foi constatado que nenhum aluno finalizou o curso. Do outro lado, estão os cursos de Medicina (90\%), Enfermagem (86\%), Biomedicina (85\%) e Direito $(79 \%)$ apresentaram maiores taxa de conclusão, tendo como características em comum que todos são bacharelados e com elevada demanda na universidade.

Dos alunos que foram classificados e aprovados com as reservas de vagas, os cursos de Licenciatura em Matemática e Letras Espanhol/Português tiveram apenas um aluno beneficiado, cada, e estes concluíram os respectivos cursos. Ressalta-se que os cursos de Licenciatura em Química, Licenciatura em Geografia, Letras Inglês/Português e Bacharelado 
em Matemática não tiveram alunos cotistas, isso por serem cursos com baixa concorrência (candidato/vaga) neste processo seletivo. Por outro lado, o curso de Medicina alcançou o êxito de $100 \%$ de conclusão de alunos cotistas (Tabela 22).

Tabela 8 Distribuição da taxa de conclusão conforme cursos de graduação da UESC, segundo a forma de ingresso no ano de 2008

\begin{tabular}{|c|c|c|}
\hline \multirow{2}{*}{ Curso } & \multicolumn{2}{|c|}{ Taxa de conclusão $(\%)$} \\
\hline & $\mathrm{PU}$ & $\mathrm{RV}$ \\
\hline Administração & 50 & 63 \\
\hline Agronomia & 48 & 24 \\
\hline Bacharelado em Física & - & 20 \\
\hline Bacharelado em Matemática & - & - \\
\hline Biomedicina & 85 & 79 \\
\hline Ciência da Computação & 33 & 23 \\
\hline Ciências Biológicas & 71 & 73 \\
\hline Ciências contábeis & 50 & 47 \\
\hline Comunicação social & 64 & 75 \\
\hline Direito & 79 & 64 \\
\hline Economia & 32 & 47 \\
\hline Enfermagem & 86 & 87 \\
\hline Engenharia de Produção & 37 & 20 \\
\hline Filosofia & 16 & 50 \\
\hline História & 47 & 42 \\
\hline LEA & 60 & 40 \\
\hline Letras Espanhol/Português & 68 & 100 \\
\hline Letras Inglês/Português & 59 & - \\
\hline Licenciatura em Ciências Biológicas & 45 & 74 \\
\hline Licenciatura em Educação Física & 48 & 70 \\
\hline Licenciatura em Física & 20 & 11 \\
\hline Licenciatura em Geografia & 53 & - \\
\hline Licenciatura em Matemática & 18 & 100 \\
\hline Licenciatura em Pedagogia & 78 & 50 \\
\hline Licenciatura em Química & 48 & - \\
\hline Medicina & 90 & 100 \\
\hline Medicina Veterinária & 64 & 56 \\
\hline Total & 50 & 56 \\
\hline
\end{tabular}

Nota 1: Não está incluso os alunos ingressantes nos cursos a partir da escolha da segunda opção de curso.

Nota: 2: Entende-se que Processo Universal (PU) engloba apenas os não-optantes por reserva de vagas (RV).

Fonte: Elaborado a partir de dados da GESEOR. 
A universidade e a sociedade, de modo geral, apontam que os alunos classificados com as cotas teriam um desempenho inferior perante os demais. Todavia, no que se refere à conclusão dos cursos, os dados da Universidade Estadual de Santa Cruz apontam que 56\% dos alunos que ingressaram com as reservas de vagas conseguiram finalizar o curso com sucesso. Acredita-se que esse público aproveita a oportunidade de cursar o ensino superior, como uma das únicas formas de melhoria de vida, sendo a efetivação do curso superior um meio que possibilite ocupar melhores posições no mercado de trabalho.

Ao discutir o desempenho dos alunos de três turmas da Universidade de Brasília em 2004, 2005 e 2006, mediante processo seletivo com as reservas de vagas e processo universal, Veloso (2009) comparou as médias de três áreas d e conhecimento (Humanidades, Ciências e Saúde) em cada turma. Chegando à conclusão que nas Humanidade e Ciências, a vantagem dos cotistas sobre os não-cotistas concentrou-se nos cursos socialmente menos valorizados, mas isso não ocorreu na área de Saúde (VELOSO, 2009, p. 641). Em termos de diferenças substantivas não houve uma sistemática superioridade dos não-cotistas, embora previssem muitos críticos do sistema de reserva de vagas.

O trabalho de Cardoso (2008) ratifica Veloso, ao mostrar pequenas as diferenças entre cotistas e não cotistas que poderia ser interpretada como irrelevantes e ressalta que a variação das notas obtidas na Universidade de Brasília é muito menor que as variações no escore na seleção do vestibular.

\section{CONSIDERAÇÕES FINAIS}

As universidades exercem função incontestável na formação dos indivíduos na sociedade contemporânea. Portanto, no decorrer dos anos, fica notório o aumento da demanda por ensino superior, isso, possivelmente em razão das novas perspectivas estabelecidas por organizações e empresas que tem como pressuposto básico para a entrada e ou permanência no mercado de trabalho a formação acadêmica

O presente estudo nos proporciona a oportunidade de fazer algumas inferências do acesso a finalização do ensino superior, para situarmos os sujeitos dessa pesquisa são os alunos que ingressaram no primeiro processo seletivo com as reservas de vagas na Universidade Estadual de Santa Cruz. Em um primeiro momento situarmos as ações desenvolvidas pela universidade para a permanência dos alunos como instrumento a evitar a evasão estudantil. Nesse sentido, para obter êxito no longo prazo, faz-se necessário muitos 
esforços e compromissos de todos, ou seja, da própria instituição, alunos, professores e comunidade acadêmica em geral.

Ressaltamos a importância da nova modalidade de ingressar nos cursos de graduação as cotas - visando trazer um público que representa parcela da sociedade exclusa dos acentos universitário e sem tal modalidade permaneceria inalterado esse quadro. Por fim, buscamos compreender em qual contexto se encontra o grupo de alunos pesquisado quanto a finalização do curso superior.

A política de ações afirmativas mostra-se como relevante instrumento para reverter a atual situação de exclusão dos indivíduos da educação superior. As políticas de cotas certamente terão importante contribuição na configuração de uma sociedade mais igualitária e justa, tornando-se imprescindível a adoção dessas políticas pelas universidades, pois tem como objetivo incluir grupos marginalizados na sociedade tais como os negros, índios e quilombolas, e dar-lhes oportunidades de exercício do princípio da igualdade.

\section{REFERÊNCIAS}

ANHAIA, B.C. Educação Superior e Inclusão Social - um estudo comparado de duas ações afirmativas no Brasil: dos debates à prática. 2013. 234 f. Dissertação (Programa de Pós-Graduação em Sociologia, Instituto de Filosofia e Ciências Humanas). Universidade Federal do Rio Grande do Sul, Porto Alegre, 2013.

CARDOSO, C. B. Estudos da política de cotas na Universidade de Brasília: uma análise do rendimento e da evasão. 2008. 134 f. Dissertação (Mestrado em Educação) - Faculdade de Educação da Universidade de Brasília, Brasília, 2008.

DOMINGUES, Petrônio. Ações afirmativas para negros no Brasil: o início de uma reparação histórica. Revista Brasileira de Educação, n. 29, p. 164-176, 2005.

GOMES, Joaquim Barbosa. O debate constitucional sobre as ações afirmativas. Ações afirmativas: políticas públicas contra as desigualdades raciais. Rio de Janeiro: DP\&A, p. 15-57, 2003.

GONÇALVES, M. A. R.; As Políticas Inclusivas no Ensino Superior: UERJ e Science Po. In: CONGRESSO LUSO AFRO BRASILEIRO DE CIÊNCIAS SOCIAIS, 11, 2011, Salvador. Anais... Salvador: UFBA, 2011. p. 14. Disponível em:

$<\mathrm{http}$ ://www.xiconlab.eventos.dype.co m.br/resources/anais/3/1307496634_ARQUIVO_doclusoafro.pdf $>$. Acessado em: 17 nov. 2014.

MARTINS, T. C. Acesso às universidades públicas e o sistema de cotas. Revista AJUFERGS, 2007. 
MOEHLECKE, S. Ação afirmativa: história e debates no Brasil. Cadernos de pesquisa, São Paulo, v. 117, n. 11, p. 197-217, 2002.

OLIVEN, A. C. Ações afirmativas, relações raciais e política de cotas nas universidades: Uma comparação entre os Estados Unidos e o Brasil. Educação, v. 30, n. 61, p. 29-51, 2007.

PERIA, M. Ação afirmativa: um estudo sobre a reserva de vagas para negros nas universidades públicas brasileiras. $O$ caso do Estado do Rio de Janeiro. 2004. 135 f. Dissertação (Programa de Pós-Graduação em Antropologia Social do Museu Nacional) Universidade Federal do Rio de Janeiro, Rio de Janeiro, 2004.

PRESTES, E. M. T; JEZINE, E; SCOCUGLIA, A. C. Democratização do Ensino Superior Brasileiro: O caso da Universidade Federal da Paraíba. Revista Lusófona de Educação, n. 21, p. 199-218, 2012.

SANTOS, J. P. F. Ações afirmativas e igualdade racial: a contribuição de direito na construção de um Brasil diverso. Edições Loyola, 2005.

SILVA, S. S. Trajetórias de estudantes da rede pública que ingressam, permanecem e obtém êxito numa universidade pública. 2012. 146 f. Dissertação (Programa de PósGraduação em Educação) - Universidade Federal do Rio Grade do Norte, Natal, 2012.

SILVÉRIO, V. R. Ação afirmativa e o combate ao racismo institucional no Brasil. Cadernos de Pesquisa, v. 117, p. 219-246, 2002.

SOUSA, O. F. As ações afirmativas como instrumento de concretização da igualdade material. 2006. 169 f. Dissertações (Programa de Pós-Graduação em Direito, Setor de Ciências Jurídicas e Sociais) - Universidade Federal do Paraná, Curitiba, 2006.

VELLOSO. J. Cotistas e não cotistas: Rendimento de alunos da Universidade de Brasília. Cadernos de Pesquisa, v. 39, n. 137, p. 621-644, mai/ago., 2009.

Vestibular com cotas para negros na UnB: candidatos e aprovados nos exames. Núcleo de Estudos para o Ensino Superior \& Faculdade de Educação, UnB, 2005. 